\title{
Endothelial shear stress and vascular remodeling in bioresorbable scaffold and metallic stent
}

\author{
Erhan Tenekecioglu $^{\text {a,1 }}$, Yuki Katagiri ${ }^{\text {b, }}{ }^{\text {, Kuniaki Takahashi }}{ }^{\mathrm{b}}$, Mariusz Tomaniak ${ }^{\mathrm{a}, \mathrm{c}}$, \\ Dariusz Dudek $^{\mathrm{d}}$, Angel Cequier ${ }^{\mathrm{e}}$, Didier Carrié ${ }^{\mathrm{f}}$, Andrés Iñiguez ${ }^{\mathrm{g}}$,
} Rinse Johannes van der Schaaf ${ }^{\mathrm{h}}$, Marcello Dominici ${ }^{\mathrm{i}}$, Ad J.van Boven ${ }^{\mathrm{j}}$, Steffen Helqvist ${ }^{\mathrm{k}}$, Manel Sabaté $^{1}$, Andreas Baumbach ${ }^{\mathrm{m}}$, Jan J. Piek ${ }^{\mathrm{b}}$, Joanna J. Wykrzykowska ${ }^{\mathrm{b}}$, Pieter Kitslaar ${ }^{\mathrm{n}}$, Jouke Dijkstra $^{\mathrm{n}}$, Johan H.C. Reiber ${ }^{\mathrm{n}}$, Bernard Chevalier ${ }^{\circ}$, Dilek Ural ${ }^{\mathrm{p}}$, Kerem Pekkan ${ }^{\mathrm{q}}$, Christos V. Bourantas ${ }^{\text {r,s }}$, Frank Gijsen ${ }^{\mathrm{t}}$, Yoshinobu Onuma ${ }^{\mathrm{a}}$, Ryo Torii ${ }^{\mathrm{u}}$, Patrick W. Serruys ${ }^{\mathrm{v}, \mathrm{w}, \text { ** }}$

a Department of Interventional Cardiology, Erasmus University Medical Center. Thoraxcenter, Rotterdam, the Netherlands

${ }^{\mathrm{b}}$ Department of Cardiology Amsterdam UMC, University of Amsterdam, Amsterdam, the Netherlands

${ }^{\mathrm{c}}$ First Department of Cardiology, Medical University of Warsaw, Warsaw, Poland

${ }^{\mathrm{d}}$ Department of Interventional Cardiology, Jagiellonian University, Krakow, Poland

${ }^{\mathrm{e}}$ Bellvitge University Hôspital, Barcelona, Spain

${ }^{\mathrm{f}}$ Hopital de Rangueil, Toulouse, France

${ }^{\mathrm{g}}$ Interventional Cardiology Unit, Cardiology Department, Hospital Alvaro Cunqueiro, University Hospital of Vigo, Vigo, Spain

${ }^{\mathrm{h}}$ Onze Lieve Vrouwe Gasthuis, Amsterdam, the Netherlands

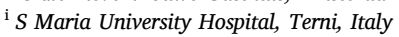

${ }^{\mathrm{j}}$ Medical Center Leeuwarden, Leeuwarden, the Netherlands

${ }^{\mathrm{k}}$ Rigshospitalet, University of Copenhagen, Copenhagen, Denmark

${ }^{1}$ Biomédiques August Pi I Sunyer, University of Barcelona, Barcelona, Spain

${ }^{\mathrm{m}}$ Bristol Heart Institute, Bristol, United Kingdom

${ }^{\mathrm{n}}$ LKEB-Division of Image Processing, Department of Radiology, Leiden University Medical Centre, Leiden, the Netherlands

${ }^{\circ}$ Ramsay Générale de Santé, Institut Cardiovasculaire Paris Sud, Massy, France

${ }^{\mathrm{p}}$ Department of Cardiology, Koç University, Istanbul, Turkey

${ }^{\mathrm{q}}$ Department of Mechanical Engineering, Koç University, Istanbul, Turkey

${ }^{\mathrm{r}}$ Department of Cardiology, University College of London Hospitals, London, United Kingdom

${ }^{s}$ Department of Cardiology, Barts Heart Centre, London, United Kingdom

${ }^{\mathrm{t}}$ Department of Biomedical Engineering, Erasmus University Medical Center, Thoraxcenter, Rotterdam, the Netherlands

${ }^{u}$ Department of Mechanical Engineering, University College London, United Kingdom

${ }^{\mathrm{v}}$ Imperial College London, London, United Kingdom

${ }^{\mathrm{w}}$ Department of cardiology, National University of Ireland, Galway (NUIG), Galway, Ireland

\section{A R T I C L E I N F O}

\section{Keywords:}

Stenting

Bioresorbable scaffold

Vessel remodeling

Shear stress

\begin{abstract}
A B S T R A C T
Background and aims: The impact of endothelial shear stress (ESS) on vessel remodeling in vessels implanted with bioresorbable scaffold (BRS) as compared to metallic drug-eluting stent (DES) remains elusive. The aim of this study was to determine whether the relationship between ESS and remodeling patterns differs in BRS from those seen in metallic DES at 3-year follow-up.

Methods: In the ABSORB II randomized trial, lesions were investigated by serial coronary angiography and intravascular ultrasound (IVUS). Three-dimensional reconstructions of coronary arteries post-procedure and at 3 years were performed. ESS was quantified using non-Newtonian steady flow simulation. IVUS cross-sections in device segment were matched using identical landmarks.

Results: Paired ESS calculations post-procedure and at 3 years were feasible in 57 lesions in 56 patients. Postprocedure, median ESS at frame level was higher in BRS than in DES, with marginal statistical significance $(0.97 \pm 0.48 v s .0 .75 \pm 0.39 \mathrm{~Pa}, p=0.063)$. In the BRS arm, vessel area and lumen area showed larger increases
\end{abstract}

\footnotetext{
* Corresponding author. Imperial College London, P.O. Box 2125, 3000 CC, Rotterdam, the Netherlands.

E-mail address: patrick.w.j.c.serruys@gmail.com (P.W. Serruys).

1 These authors contributed equally to this work.
} 
in the highest tercile of median ESS post-procedure as compared to the lowest tercile. In contrast, in DES, no significant relationship between median ESS post-procedure and remodeling was observed. In multivariate analysis, smaller vessel area, larger lumen area, higher plaque burden post-procedure, and higher median ESS post-procedure were independently associated with expansive remodeling in matched frames. Only in BRS, younger age was an additional significant predictor of expansive remodeling.

Conclusions: In a subset of lesions with large plaque burden, shear stress could be associated with expansive remodeling and late lumen enlargement in BRS, while ESS had no impact on vessel dimension in metallic DES.

\section{Introduction}

Given the transient scaffolding and recovery of vasomotion in the instrumented vessels, bioresorbable scaffolds (BRS) have emerged as a potential solution for drawbacks of metallic drug-eluting stents (DES) that causes permanent vessel straightening and loss of compliance, dynamic vessel remodeling and mechanotransduction [1]. These shortcomings may influence vessel wall metabolism and contribute to late degeneration of intra-device neointima leading to neoatherosclerotic lesion formation. Despite unprecedented results from ABSORB II that made the Absorb BVS out of the market, the trials on BRS are ongoing non-stop [2].

During resorption of polymeric scaffold, late luminal enlargement with expansive remodeling has been documented [3], but biological and/or physiological determinants of this morphological and anatomical processes are still elusive.

Arterial remodeling, defined briefly as any change in vessel wall structure, is a complex process depending on several endogenous (plaque characteristics, oxidative stress, inflammation, calcification and collagen deposition) and environmental factors [4]. Homeostatic response of the vessel wall to hemodynamic and mechanical triggers is the main underlying process of arterial remodeling [5]. The relationship between lumen area, plaque-media area, and vessel area is at the foundation of the Glagov's principle of compensatory expansive remodeling of the external elastic membrane (EEM) [5]. Regarding the modifications in these three compartments, there are miscellaneous scenarios of expansive or constrictive remodeling, increase or decrease in plaque/media and increase/decrease in lumen area [3,6]. Endothelial shear stress (ESS), the frictional force at the endothelial surface produced by flowing blood, is a preliminary cue for vessel remodeling. ESS is a dynamic entity related to macroscopic changes in blood flow $[7,8]$.

The present study is the first to analyze and compare the impact of shear stress both in BRS and metallic stents. The researchers tried to see the long-term repercussions of biodegradable scaffold and metallic stent on the vessel wall and the change in shear stress within the treated vessel segments in both stent types. Detailed analyses of the remodeling have been previously reported by our group, as well as the potential independent determinant of the remodeling [3]. The purposes of the present study were to determine whether ESS post-procedure is associated with vessel remodeling in instrumented arterial segments, and whether the relationship between ESS and remodeling patterns differs in BRS from those seen in metallic DES at 3-year follow-up.

\section{Patients and methods}

\subsection{Study design and patient selection}

The ABSORB-II trial is a prospective, single-blind, multicenter trial that randomized 501 patients to percutaneous coronary intervention (PCI) with implantation of either Absorb BRS or Xience metallic DES in a 2:1 fashion [9]. The protocol mandated documentary intravascular ultrasound (IVUS) pre-procedure and post-procedure and at 3-year follow-up.

\subsection{Data acquisition and analysis}

Two-dimensional (2D) quantitative coronary angiography (QCA) and IVUS data acquisition have been described previously [9]. For the present study, to correspond with the cardiac phase analyzed in QCA, the electrocardiogram (ECG)-gated end-diastolic cross-sectional frames in IVUS were used.

All IVUS pullbacks were analyzed off-line by the independent core lab using the commercially available software (QIVUS version 2.2, Medis, Leiden, the Netherlands). The methods for quantitative analysis of IVUS have been reported previously [10]. As in the conventional analysis on IVUS, the device segments as well as the segments $5 \mathrm{~mm}$ proximal and distal to the device, were analyzed since beyond these regions, the effect of trauma by the device edge to trigger neointima growth is inexistent [11]. After scanning he population ( $\mathrm{n}=501$ patients with 546 lesions), the 100 cases with 2 time points ( $n=200$ lesions) (post-implantation and 3-years), which fulfilled both criteria of (1) suitable coronary angiograms (minimal foreshortening and $\geq 25^{\circ}$ angle difference between two angiograms) and (2) IVUS-VH (at least $5 \mathrm{~mm}$ edge segments proximal and distal to the treated segment both post-implantation and at 3-years follow-up) were included in the study.

The increase or decrease in vessel area (or EEM area) defines the type of vascular remodeling, constrictive or expansive. In order to compare the BRS and metallic stent and due to the difficulty to measure the neointima in the biodegraded scaffold at 3-year, the intra-scaffold/stent neointima was incorporated in the metric of "plaque/media = vessel area-lumen area" [3]. In a previous study [12], performed on ex vivo human coronary arteries, relative range of inter-observer reproducibilities of measurements for lumen, plaque-media, and vessel cross sectional areas based on two standard deviations of their measurements were determined. Based on those relative ranges of inter-observer reproducibility measurements by Muramatsu et al. [12], Serruys et al. [3] defined relative changes in lumen area, plaque-media-area and vessel area as $\pm 15 \%, \pm 22 \%, \pm 12 \%$, respectively. In compliance with these relative values of reproducibility by Muramatsu et al. [12] and relative changes of lumen, plaque-media and vessel area by Serruys et al. [3], there have been 9 theoretical patterns of vessel/lumen/plaque remodeling based on increase, no change, and decrease in each of these three parameters [3,6]. In the present study, vessel remodeling was defined as any positive or negative change in vessel area, assessed in a continuous fashion, without the use of binary cut-off criteria.

\subsection{Coronary artery reconstruction}

Three-dimensional (3D) model reconstruction of coronary artery was based on 3D-QCA of the vessel implanted with the device and coregistration of lumen contour of IVUS onto the centerline of the vessel reconstructed in 3D-QCA [13]. Following the recruitment of the cases that fulfilled the criteria of coronary angiogram and IVUS $(n=200$ lesions), during the 3D vessel reconstruction for CFD work, 34 vessels could not be $3 \mathrm{D}$ reconstructed due to various technical points during the main vessel-side branch co-registration process.

Three-dimensional QCA was performed using QAngioXA-3D (version-1.3 Medis, Leiden, the Netherlands).Two post-procedural end- 
diastolic angiographic images with at least a $25^{\circ}$-angle difference, and with minimal foreshortening were selected. In order to adjust for the effect of vessel curvature on the local hemodynamic forces [14], the proximal native vessel segment from its ostium was incorporated into the 3D-model (Fig. 1A).

Side-branch (SB) proximal to the device segment (within a distance of 3 times the diameter of proximal-SB), SB in the device segment and SB distal to the device segment (within a distance of one-diameter of the distal-SB) were included to account for the effect of flow division and the effect of any flow disturbance caused by the carina zone of the SB. To achieve a realistic effect of flow division [15], side-branches $\geq 1.5 \mathrm{~mm}$ in QCA measurements were reconstructed and incorporated into the 3D-model (Fig. 1B and C).

Following 3D-QCA, lumen contours by IVUS within device segment and segments $5 \mathrm{~mm}$ proximal and distal to the device were co-registered onto the 3D-QCA centerline using 3D-Angio-IVUS Co-registration (Medis, Leiden, the Netherlands) (Fig. 1D) and a 3D-surface model was reconstructed using QAngio-CT 3D-Workbench (version-1.3.0.2, Medis, Leiden, the Netherlands) (Fig. 1E).

\subsection{Computational fluid dynamic study}

Following 3D-reconstruction of the coronary artery, the computational fluid dynamics (CFD) mesh was generated using ANSYS ICEM CFD 17.0 (ANSYS,Inc. Canonsburg, Pennsylvania). A typical cell size of 0.1 $\mathrm{mm}$ was used and three prism layers at the wall were constructed, resulting in a mesh size of $\sim 2 \times 10^{6}$ cells. In order to incorporate its shear-thinning behavior, blood was modeled as a non-Newtonian fluid by applying Carreau model with the parameters taken from Seo et al. [16]. The blood density was set to $1060 \mathrm{~kg} / \mathrm{m}^{3}$. The vessel wall was modeled as rigid and no-slip condition was imposed at the wall. For the inflow and outflow conditions in the main vessel and side-branches, flow rates were estimated based on the diameter of the main vessel and SB, following the relationship derived from in vivo observations (scaling approach) [15,17]. During the scaling approach, the inlet velocities (V) were determined using the flow rates $(Q)$ calculated by the diameters of the related vessel segments $[15,17]$ and cross-sectional area (A) with the formula of $\mathrm{Q}=\mathrm{V} / \mathrm{A}$ (Supplementary materials). Poiseuille velocity profile was prescribed at the inlet based on the scaled flow rate. Since the association of ESS with vessel remodeling is based on time-averaged data over 3 years, we focused on steady flow simulations [18]. A finite-volume solver was used to perform steady-state simulations using standard numerical techniques (ANSYS Fluent v17.0,ANSYS, Inc. Canonsburg, Pennsylvania) (Fig. 1F).

In post-processing the CFD result, cross-sections of the CFD models were located perpendicularly onto the lumen centerline and matched to the IVUS frames using in-house algorithms to be able to export mean, median, minimum, and maximum ESS at frame level (a distance of adjacent frames: median 0.42 [interquartile range $0.38,0.50$ ] $\mathrm{mm}$ ). During the co-localization and orientation between the cross-sections from 3D CFD model and IVUS frames, side-branches were utilized incorporating the horizontal angle degree of the SB with the centerline.

During volume meshing, due to geometrical artefacts in bifurcation zones, 6 models could not be meshed, and due to low mesh quality 14 models could not be simulated. Following the CFD simulation of 146 lesions, 14 models could not be processed during the post-processing step. At the end, there were 57 patients both with post-implantation and 3 year shear stress simulation successfully post-processed.

\subsection{Matching frames among pre-procedure, post-procedure and 3-year follow-up}

IVUS cross-sections were matched for pre-procedure, post-procedure and 3-year follow-up using identical landmarks such as scaffold/stent edges, side-branches and calcium locations so that serial changes of the lumen, plaque, vessel area and ESS from post-procedure to 3-year could be analyzed at a cross-sectional level. Pre-procedural compositional information in IVUS-virtual histology (VH) was also matched with
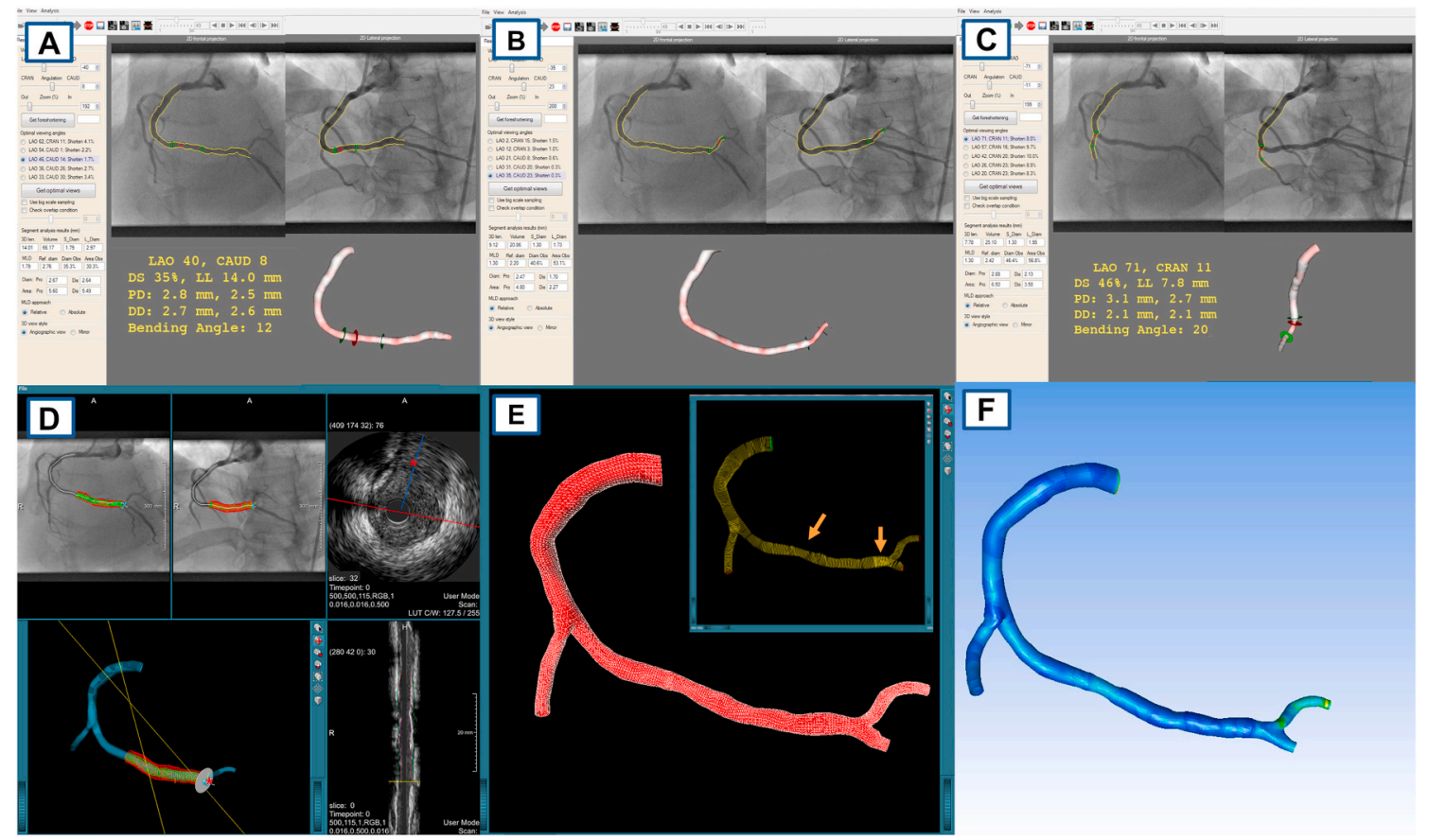

Fig. 1. Analysis steps for computational fluid dynamics (CFD) simulation in coronary artery.

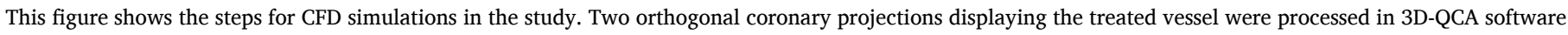

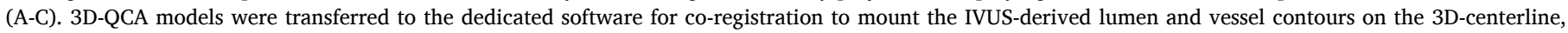

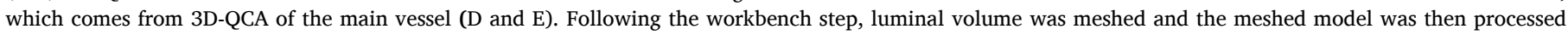

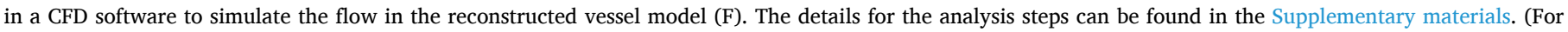
interpretation of the references to colour in this figure legend, the reader is referred to the Web version of this article.) 
frames at later time points. Matching was performed using dedicated software [QCU-CMS software version-4.69 (Leiden University Medical Center, Leiden, Netherlands)] [19].

\subsection{Statistical analysis}

At patient or device level, categorical variables were compared using Pearson's chi-square test or Fischer's exact test, as appropriate. Continuous variables were compared using Student t-test.

Analyses were carried out using variables per each cross-section (frame) in device segment. Frame-level ESS between devices or between post-procedure and at 3-year was compared using linear mixed model, taking into account the clustering nature of the data within device or patient. Terciles of median-ESS at a frame level were determined based on pooled cross-sectional data.The relationships between terciles of post-procedural median-ESS and cross-sectional changes of the lumen, plaque, vessel area, and plaque burden were analyzed by linear mixed-model adjusted for multiple comparisons by Bonferroni correction.

Multivariate linear mixed-model predicting vessel area change was constructed using variables with $p$-value $<0.10$ in univariate analysis. Post-procedural median-ESS was forced to enter in the model as a primary variable of interest. A $p$-value $<0.05$ was considered statistically significant. Statistical analyses were performed with SPSS version24.0.0.2 (IBM,Armonk, New York).

\section{Results}

\subsection{Baseline patient characteristics, angiographic and IVUS results}

Out of 546 lesions in 501 patients enrolled in ABSORB-II trial, paired ESS post-procedure and at 3 years were analyzable in 35 lesions in 35 patients in the BRS arm and 22 lesions in 21 patients in the DES arm. The study flowchart is shown in Fig. 2.

Baseline (pre-procedure) clinical and lesion characteristics are tabulated in Table 1. Patient, lesion and procedural features were well balanced between two device groups. The pre-procedural IVUS parameters were also comparable between the study groups (Supplementary Table 1).

Post implantation and at 3 years, both mean and minimum luminal diameters by QCA were smaller in the BRS arm than in the DES arm (Supplementary Table 2).

Mean and minimum lumen area post-implantation, as measured by IVUS, were smaller in the BRS arm, when compared to the metallic DES arm (Supplementary Table 3). Post-implantation mean vessel area was significantly smaller in BRS arm than in DES arm (12.78 \pm 3.20 vs. $14.97 \pm 2.98, p=0.012$ ). However, at 3-year follow-up, mean vessel area was no longer statistically different, as a result of expansive remodeling in BRS arm and constrictive remodeling in DES arm in combination with some loss in lumen area (change in mean vessel area: $+0.78 \pm 1.49$ vs. $-0.66 \pm 1.64 \mathrm{~mm}^{2}, p=0.001$ ).

\subsection{Endothelial shear stress: comparison between devices and serial evolution}

Table 2, Fig. 3 and Supplementary Figure 1 show changes in the lumen, plaque, vessel area $\left(\mathrm{mm}^{2}\right)$ and plaque burden (\%) over 3 years among the terciles of ESS post-procedure $(\sim 0.658$; 0.658-0.953; 0.953 Pa). In BRS arm, the lowest-tercile of ESS showed a decrease in lumen area as opposed to late lumen enlargement in the intermediateand the highest-terciles. There is a significant difference in plaque-media area, increasing in BRS $\left(+0.64 \pm 1.10 \mathrm{~mm}^{2}\right)$ and decreasing in Xience $\left(-0.46 \pm 1.22 \mathrm{~mm}^{2}\right)$. The vessel segments implanted with BRS demonstrated a higher ESS as compared to those with DES both postprocedure and at 3 years (Supplementary Figure 1).

In BRS, increase in plaque area from post-procedure to 3-year follow up was not different among the three terciles of ESS post-procedure, and vessel area showed a larger increase in the highest-tercile as compared to the lowest-tercile of ESS post-procedure. Consequently, the lowest tercile of ESS post-procedure showed an increase in plaque burden $(+5.36 \pm 8.98 \%)$ significantly larger than intermediate $(1.86 \pm 8.09 \%)$ or highest $(0.72 \pm 7.46 \%)$ tercile of ESS post-procedure. In contrast, in DES arm, there was no significant difference in change in the lumen, plaque vessel areas and plaque burden amongst the 3 terciles of ESS

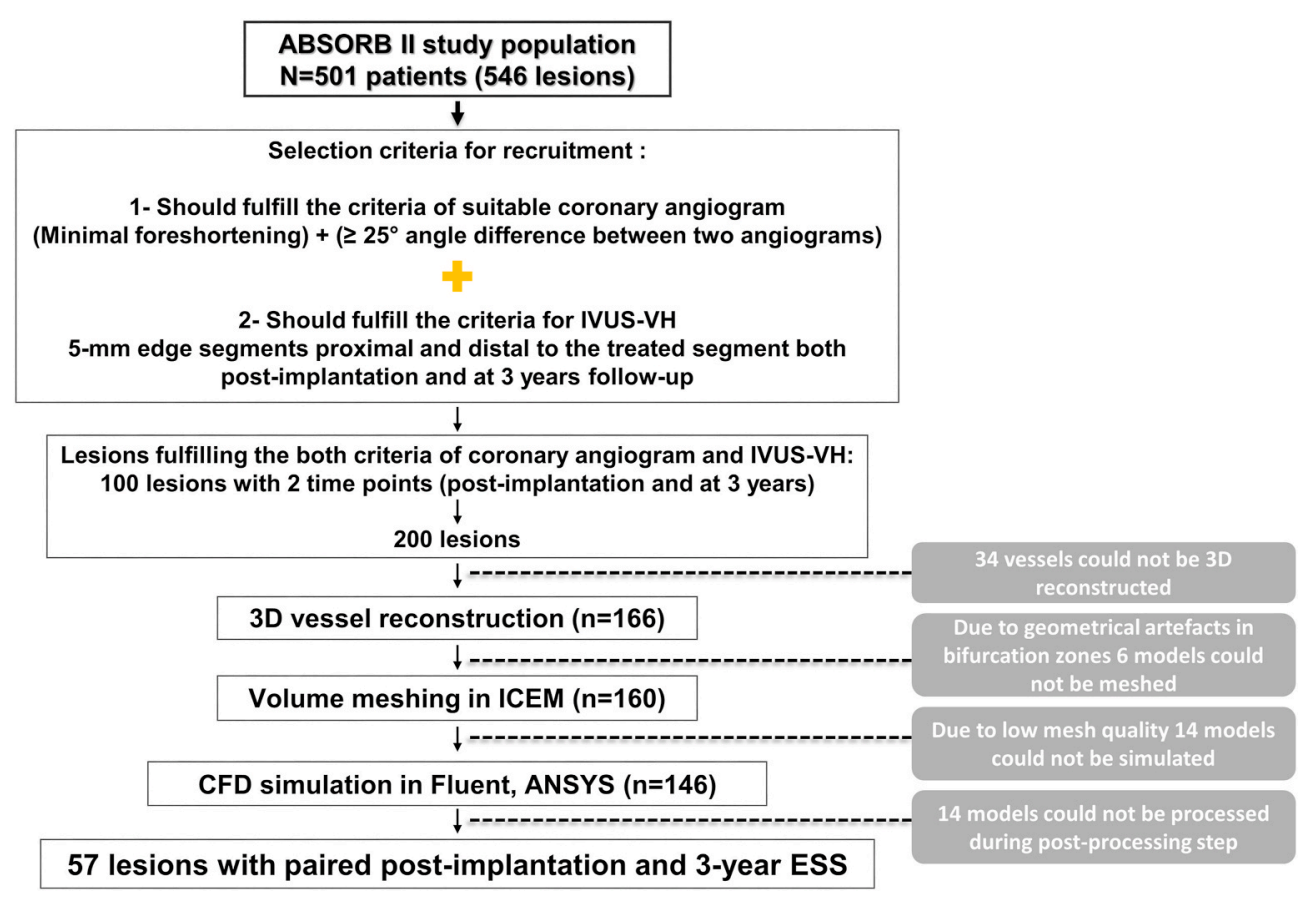

Fig. 2. Study flow-chart.

$\mathrm{CFD}=$ computational fluid dynamics, ESS = endothelial shear stress, IVUS = intravascular ultrasound. (For interpretation of the references to colour in this figure legend, the reader is referred to the Web version of this article.) 
Table 1

Baseline patient, lesion characteristics and procedure details.

\begin{tabular}{|c|c|c|c|}
\hline & BRS & DES & $\begin{array}{l}p \\
\text { value }\end{array}$ \\
\hline Patient characteristics & $\begin{array}{l}35 \\
\text { patients }\end{array}$ & $\begin{array}{l}21 \\
\text { patients }\end{array}$ & \\
\hline Age (years) & $\begin{array}{l}60.34 \pm \\
8.09\end{array}$ & $\begin{array}{l}57.57 \pm \\
10.63\end{array}$ & 0.275 \\
\hline Male & $20(57.1)$ & $20(95.2)$ & 0.002 \\
\hline Current smoking & $9(25.7)$ & $5(23.8)$ & 1.000 \\
\hline Hypertension requiring medication & $27(77.1)$ & $15(71.4)$ & 0.752 \\
\hline Dyslipidemia requiring medication & $28(80.0)$ & $13(61.9)$ & 0.212 \\
\hline Diabetes & $8(22.9)$ & $1(4.8)$ & 0.132 \\
\hline Unstable angina & $4(11.4)$ & $3(14.3)$ & 1.000 \\
\hline Prior MI & $8(22.9)$ & $5(23.8)$ & 1.000 \\
\hline Previous PCI & $13(37.1)$ & 9 (42.9) & 0.780 \\
\hline Obesity (BMI $\geq 30 \mathrm{~kg} / \mathrm{m}^{2}$ ) & $8(22.9)$ & $7(33.3)$ & 0.534 \\
\hline Lesion characteristics & 35 lesions & 22 lesions & \\
\hline \multicolumn{4}{|l|}{ Lesion location } \\
\hline Right coronary artery & $10(28.6)$ & $7(31.8)$ & 0.415 \\
\hline Left anterior descending & $15(42.9)$ & $12(54.5)$ & \\
\hline Left circumflex artery & $10(28.6)$ & $3(13.6)$ & \\
\hline \multicolumn{4}{|l|}{ Lesion classification } \\
\hline A & $1(2.9)$ & $0(0.0)$ & 0.628 \\
\hline B1 & $13(37.1)$ & $10(45.5)$ & \\
\hline B2 & $21(60.0)$ & $12(54.5)$ & \\
\hline \multicolumn{4}{|l|}{ Procedural details } \\
\hline Pre-dilatation performed & $\begin{array}{l}35 \\
(100.0)\end{array}$ & $21(95.5)$ & 0.386 \\
\hline $\begin{array}{l}\text { Nominal diameter of pre-dilatation balloon } \\
(\mathrm{mm})\end{array}$ & $\begin{array}{l}2.62 \pm \\
0.39\end{array}$ & $\begin{array}{l}2.63 \pm \\
0.38\end{array}$ & 0.930 \\
\hline $\begin{array}{l}\text { Maximal pressure during pre-dilatation } \\
\text { (atm) }\end{array}$ & $\begin{array}{l}12.23 \pm \\
3.25\end{array}$ & $\begin{array}{l}12.71 \pm \\
2.63\end{array}$ & 0.565 \\
\hline Nominal diameter of device (mm) & $\begin{array}{l}3.01 \pm \\
0.30\end{array}$ & $\begin{array}{l}3.09 \pm \\
0.20\end{array}$ & 0.297 \\
\hline Length of implanted device (mm) & $\begin{array}{l}21.77 \pm \\
6.79\end{array}$ & $\begin{array}{l}19.36 \pm \\
3.51\end{array}$ & 0.085 \\
\hline $\begin{array}{l}\text { Maximal pressure during device } \\
\text { implantation (atm) }\end{array}$ & $\begin{array}{l}13.91 \pm \\
2.37\end{array}$ & $\begin{array}{l}13.36 \pm \\
2.56\end{array}$ & 0.411 \\
\hline Expected device diameter (mm) & $\begin{array}{l}3.36 \pm \\
0.32\end{array}$ & $\begin{array}{l}3.30 \pm \\
0.28\end{array}$ & 0.523 \\
\hline Post-dilatation performed & $23(65.7)$ & $17(77.3)$ & 0.391 \\
\hline $\begin{array}{l}\text { Nominal diameter of post-dilatation } \\
\text { balloon }(\mathrm{mm})\end{array}$ & $\begin{array}{l}3.16 \pm \\
0.37\end{array}$ & $\begin{array}{l}3.29 \pm \\
0.30\end{array}$ & 0.234 \\
\hline $\begin{array}{l}\text { Maximal pressure during post-dilatation } \\
\text { (atm) }\end{array}$ & $\begin{array}{l}15.65 \pm \\
3.24\end{array}$ & $\begin{array}{l}16.94 \pm \\
3.88\end{array}$ & 0.260 \\
\hline $\begin{array}{l}\text { Expected diameter of post-dilatation } \\
\text { balloon }(\mathrm{mm})\end{array}$ & $\begin{array}{l}3.29 \pm \\
0.39\end{array}$ & $\begin{array}{l}3.39 \pm \\
0.32\end{array}$ & 0.431 \\
\hline $\begin{array}{l}\text { Expected diameter of post-dilatation/ } \\
\text { device balloon throughout procedure (mm) }\end{array}$ & $\begin{array}{l}3.40 \pm \\
0.33\end{array}$ & $\begin{array}{l}3.37 \pm \\
0.29\end{array}$ & 0.732 \\
\hline Expected balloon-artery ratio & $\begin{array}{l}1.21 \pm \\
0.13\end{array}$ & $\begin{array}{l}1.17 \pm \\
0.12\end{array}$ & 0.176 \\
\hline Post-procedural patient related factors & $\begin{array}{l}35 \\
\text { patients }\end{array}$ & $\begin{array}{l}21 \\
\text { patients }\end{array}$ & \\
\hline Mean LDL cholesterol (mmol/L) & $\begin{array}{l}2.35 \pm \\
0.62\end{array}$ & $\begin{array}{l}2.52 \pm \\
0.84\end{array}$ & 0.374 \\
\hline
\end{tabular}

$\mathrm{BMI}=$ body mass index, BRS = bioresorbable scaffold, DES = drug-eluting stent, $\mathrm{LDL}=$ low-density lipoprotein, $\mathrm{MI}=$ myocardial infarction, $\mathrm{PCI}=$ percutaneous coronary intervention.

post-procedure (Fig. 3).

The relationship between vessel area, lumen area and plaque burden at the frame level in case of expansive remodeling is presented in Fig. 4. While there was a linear relationship between vessel area change and lumen area change in Absorb, no such relationship was detected in metallic Xience. There was a negative relationship between the change in lumen area and plaque burden both in BRS and metallic stent. In Absorb, wall shear stress was inversely related to luminal area. However, there was no relationship between wall shear stress and luminal area in metallic DES.

\subsection{Predictors of vessel remodeling}

The results of univariate analysis predicting vessel area change $\left(\mathrm{mm}^{2}\right)$ over 3 years in linear mixed-model are tabulated in Supplementary Table 4. Following forced entry of variables with $p<0.10$ in univariate analyses, as well as median-ESS post-procedure, a multivariate model was constructed. Overall, smaller vessel area, larger lumen area, higher plaque burden post-procedure, and higher median ESS postprocedure were independently associated with expansive remodeling in matched frames (Table 3 and Fig. 5). Only in BRS, younger age was an additional significant predictor of expansive remodeling.

Regarding any heterogeneity on the ESS and remodeling throughout the length of DES and BRS; in terms of ESS there were heterogeneity between the proximal, middle and distal vessel segments only in Absorb implanted vessel segments. In metallic Xience, such heterogeneity was not identified. In Absorb, changes in VA between post-implantation and 3 -year follow up had a significant relationship to ESS in the middle zones of the device implanted vessel segments. However, in metallic Xience, there was no such relationship between ESS and VA change in either distal, middle and proximal zones of Xience implanted vessel segments (Supplementary Table 5).

\section{Discussion}

Although the bioresorbable scaffold Absorb is no longer commercially available, it is the BRS that has been the most widely used and studied, and long-term follow up of COMPARE, AIDA, ABSORB-III and -IV have still to be reported. The Absorb device is representative of a generic or class effect that will be encountered with other BRS. Any fundamental pathophysiological mechanisms investigated on this archetype of BRS, such as dismantling, remodeling, late lumen enlargement, will be probably replicated in novel scaffolds with thinner struts currently in trial. However, the Absorb remains the first historical device in which the effect of shear stress on scaffolded vessel segments has been investigated.

The main findings of the present study were: (1) The vessel segments implanted with BRS demonstrated a higher ESS as compared to those with DES both post-procedure and at 3 years; (2) overall, higher medianESS, smaller vessel area, larger lumen area, and higher plaque burden post-procedure were independently associated with expansive remodeling at long term follow-up; (3) only in BRS, younger age was an additional significant predictor of expansive remodeling. To the best of our knowledge, this is the first study investigating ESS in BRS and DES in the context of a randomized trial.

\subsection{The implication of "macro" shear stress assessed by IVUS}

In ABSORB-II, we tried to unravel the phenotype complexity of the remodeling of the lumen, plaque-media and vessel area. The lower resolution of IVUS $(80-150 \mu \mathrm{m})$, as compared to optical coherence tomography (OCT) $(10-20 \mu \mathrm{m})$, allowed us to explore ESS only in a "macro" hemodynamic environment rather than in a "micro" environment only analyzable by OCT [20]. OCT was not mandated in the ABSORB-II trial, however, in the pilot study (Absorb Cohort-B) prior to the randomized trial, the assessment of acute and chronic ( 5 years) shear stress between and on top of the struts had been carefully documented by OCT [21].

However, remodeling of vessel area and change in plaque burden cannot be captured by OCT that can only analyze endoluminal lining, whereas IVUS can measure plaque, media and vessel area (EEM area). Although bioresorption is not completed at 36 months, comparative analysis of the remodeling in Xience and Absorb at 36 months published by our group and clearly indicated that major constrictive or expansive remodeling already occurred at 3 years [3]. The current study tried to elucidate impact of the shear stress post implantation on caged and uncaged vessel wall. 
Table 2

Changes in lumen, plaque, vessel area and plaque burden in matched frames stratified by median ESS.

\begin{tabular}{|c|c|c|c|c|c|c|c|}
\hline \multirow{2}{*}{$\begin{array}{l}\text { BRS ( } \mathrm{n}=741 \\
\text { frames) }\end{array}$} & & \multirow{2}{*}{$\begin{array}{l}\text { Lowest } \\
\text { tercile }\end{array}$} & \multirow{2}{*}{$\begin{array}{l}\text { Intermediate } \\
\text { tercile }\end{array}$} & \multirow{2}{*}{$\begin{array}{l}\text { Highest } \\
\text { tercile }\end{array}$} & \multicolumn{3}{|l|}{$p$-value* } \\
\hline & & & & & $\begin{array}{l}\text { Lowest } v s \text {. intermediate } \\
\text { tercile }\end{array}$ & $\begin{array}{l}\text { Lowest } v s \text {. Highest } \\
\text { tercile }\end{array}$ & $\begin{array}{l}\text { Intermediate } v s \text {. highest } \\
\text { tercile }\end{array}$ \\
\hline \multirow[t]{6}{*}{ Median ESS } & Range (Pa) & $\sim 0.658$ & $0.658-0.953$ & $0.953 \sim$ & & & \\
\hline & Number of frames & 516 & 497 & 728 & & & \\
\hline & $\begin{array}{l}\text { Delta lumen area } \\
\left(\mathrm{mm}^{2}\right)\end{array}$ & $\begin{array}{l}-0.26 \pm \\
1.46\end{array}$ & $0.18 \pm 1.39$ & $0.57 \pm 1.28$ & 0.003 & $<0.001$ & 0.082 \\
\hline & $\begin{array}{l}\text { Delta plaque area } \\
\left(\mathrm{mm}^{2}\right)\end{array}$ & $0.92 \pm 1.54$ & $0.58 \pm 1.79$ & $0.76 \pm 1.59$ & 0.249 & 0.283 & 1.000 \\
\hline & $\begin{array}{l}\text { Delta vessel area } \\
\left(\mathrm{mm}^{2}\right)\end{array}$ & $0.66 \pm 1.79$ & $0.76 \pm 2.19$ & $1.34 \pm 1.99$ & 0.779 & 0.036 & 0.284 \\
\hline & $\begin{array}{l}\text { Delta plaque burden } \\
(\%)\end{array}$ & $5.36 \pm 8.98$ & $1.86 \pm 8.09$ & $0.72 \pm 7.46$ & 0.011 & $<0.001$ & 0.304 \\
\hline \multirow{2}{*}{$\begin{array}{l}\text { DES ( } \mathrm{n}=953 \\
\text { frames) }\end{array}$} & & Lowest & Intermediate & Highest & $p$-value* & & \\
\hline & & tercile & tercile & tercile & $\begin{array}{l}\text { Lowest } v s \text {. intermediate } \\
\text { tercile }\end{array}$ & $\begin{array}{l}\text { Lowest } v s \text {. highest } \\
\text { tercile }\end{array}$ & $\begin{array}{l}\text { Intermediate } v s \text {. highest } \\
\text { tercile }\end{array}$ \\
\hline \multirow[t]{6}{*}{ Median ESS } & Range (Pa) & $\sim 0.658$ & $0.658-0.953$ & $0.953 \sim$ & & & \\
\hline & Number of frames & 388 & 397 & 168 & & & \\
\hline & $\begin{array}{l}\text { Delta lumen area } \\
\left(\mathrm{mm}^{2}\right)\end{array}$ & $\begin{array}{l}-0.04 \pm \\
0.90\end{array}$ & $-0.16 \pm 0.84$ & $\begin{array}{l}-0.23 \pm \\
0.73\end{array}$ & 1.000 & 1.000 & 1.000 \\
\hline & $\begin{array}{l}\text { Delta plaque area } \\
\left(\mathrm{mm}^{2}\right)\end{array}$ & $\begin{array}{l}-0.01 \pm \\
2.06\end{array}$ & $-0.30 \pm 1.51$ & $\begin{array}{l}-0.21 \pm \\
1.85\end{array}$ & 0.487 & 1.000 & 1.000 \\
\hline & $\begin{array}{l}\text { Delta vessel area } \\
\left(\mathrm{mm}^{2}\right)\end{array}$ & $\begin{array}{l}-0.05 \pm \\
2.05\end{array}$ & $-0.46 \pm 1.70$ & $\begin{array}{l}-0.43 \pm \\
1.79\end{array}$ & 0.367 & 1.000 & 1.000 \\
\hline & $\begin{array}{l}\text { Delta plaque burden } \\
(\%)\end{array}$ & $0.77 \pm 7.73$ & $0.12 \pm 5.53$ & $0.22 \pm 6.74$ & 1.000 & 1.000 & 1.000 \\
\hline
\end{tabular}

*p-values were by linear mixed model, corrected for multiple comparison. ESS = endothelial shear stress.

\section{Absorb ( $n=1741$ frames)}
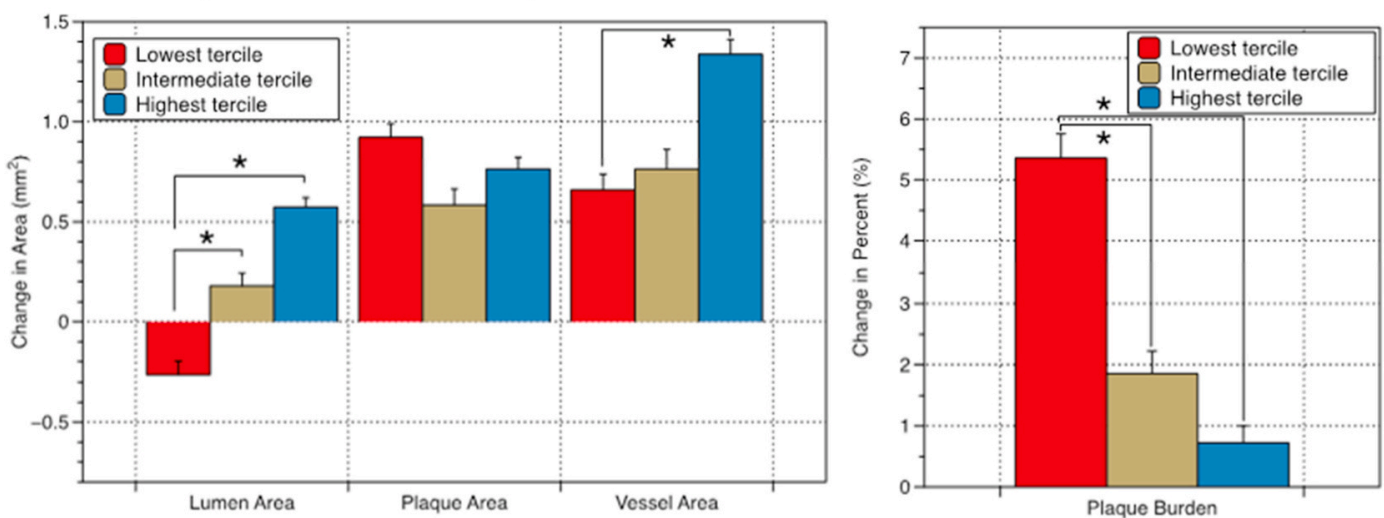

Xience ( $n=953$ frames)
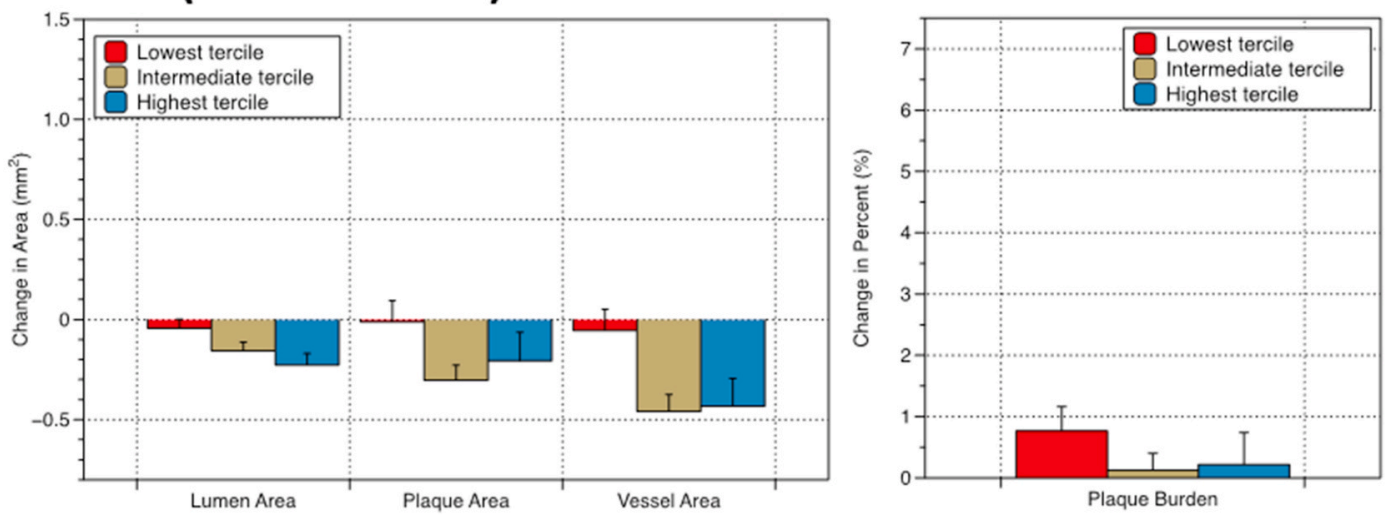

Fig. 3. Changes in lumen, plaque, vessel area and plaque burden in matched frame stratified by terciles of median-ESS post-procedure.

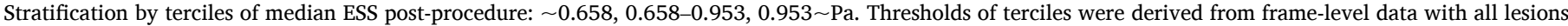

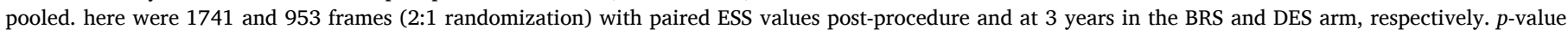

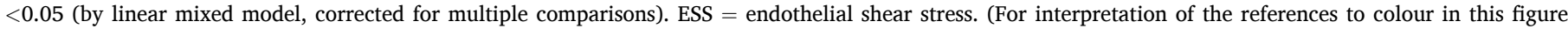
legend, the reader is referred to the Web version of this article.) 
Absorb
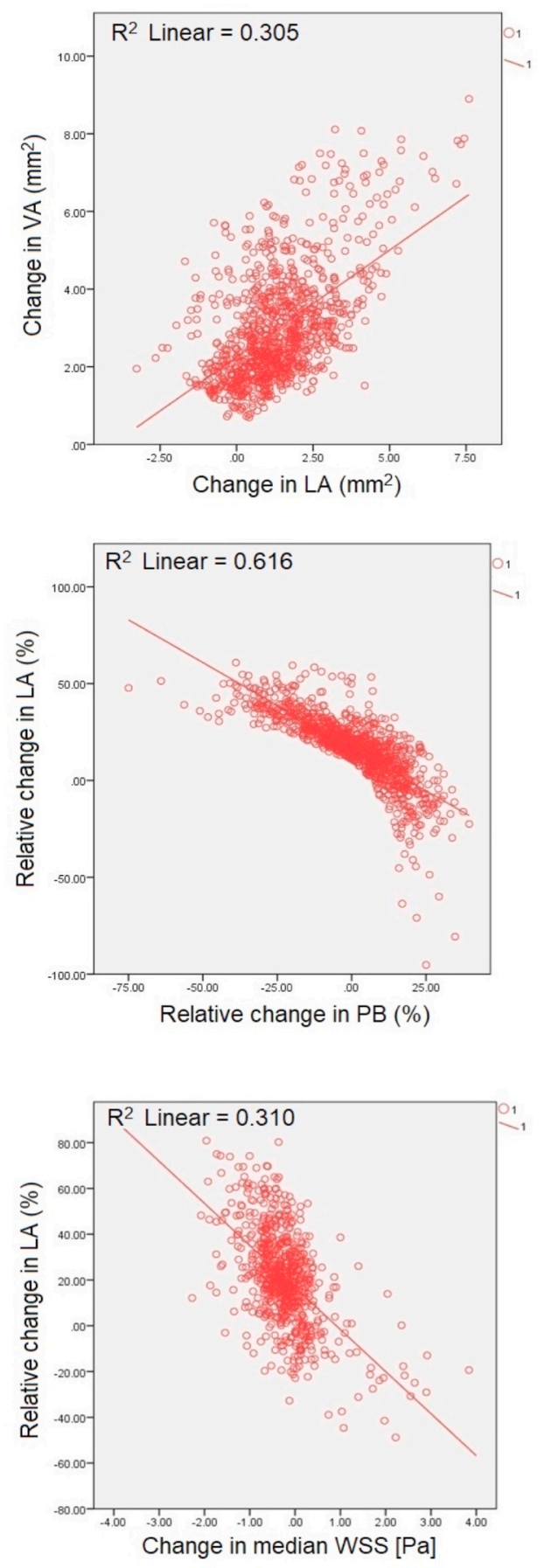

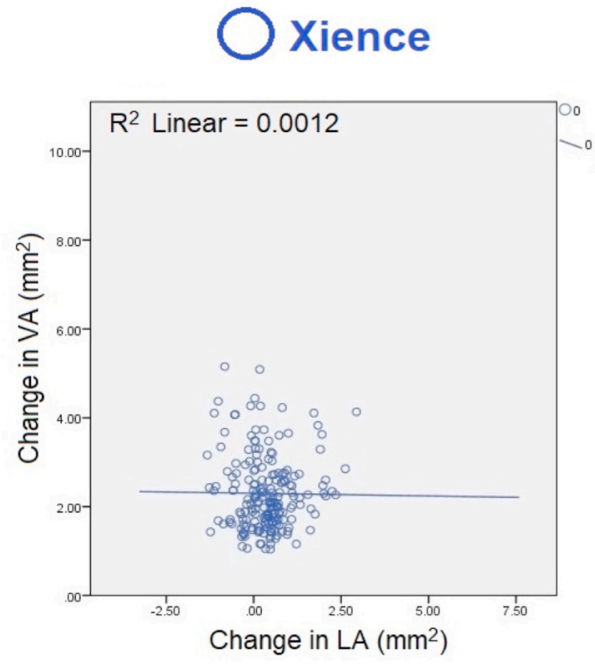

Fig. 4. Correlations between change in vessel and lumen area, between relative change in lumen area and relative change in plaque burden, and between relative change in lumen area and change in median shear stress, in patients exhibiting expansive remodeling in Absorb and metallic Xience groups, respectively (analysis at frame level).

$\mathrm{VE}=$ vessel area, LA = lumen area, $\mathrm{PB}=$ plaque burden, WSS $=$ wall shear stress. (For interpretation of the references to colour in this figure legend, the reader is referred to the Web version of this article.)
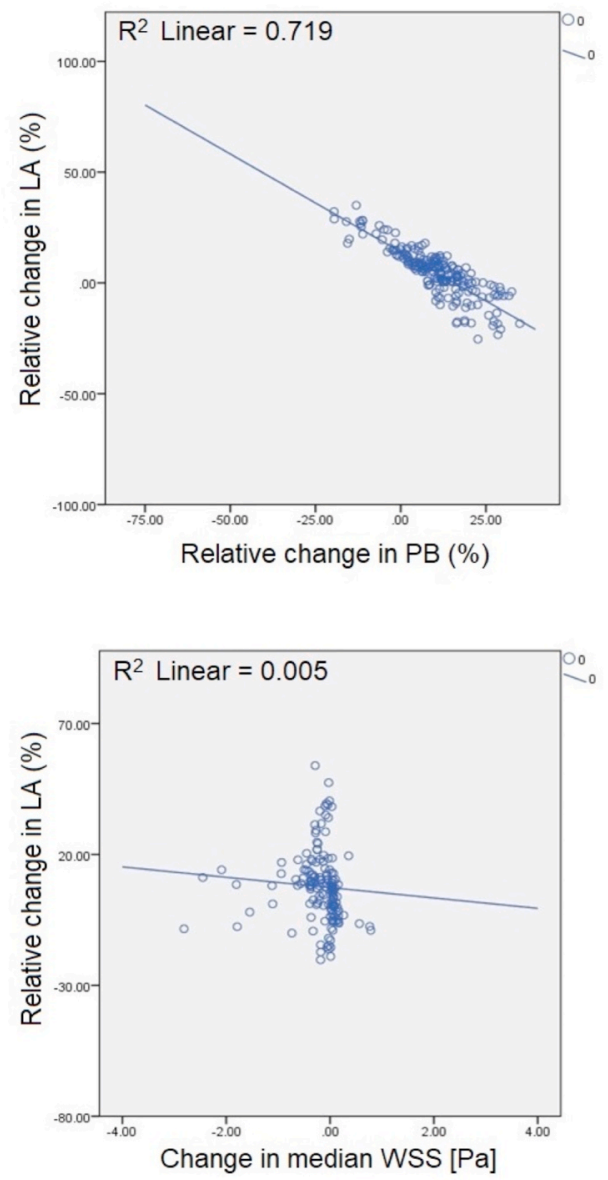

When compared to DES, smaller post-procedural lumen area in BRS (Supplementary Table 3) was expected to be the main determinant of post-procedural higher "macro" ESS by QCA-IVUS-derived 3D-coronary artery model. At 3-year follow-up, mean lumen area exhibited an increase in BRS and a decrease in DES, which resulted in comparable mean lumen area with the two devices.

In BRS, significant increase in vessel and lumen area at 3-years follow up was documented in vessels with the highest tercile of shear stress post-procedure. A significant difference in plaque-media area, increasing in BRS $\left(+0.64 \pm 1.10 \mathrm{~mm}^{2}\right)$ and decreasing in Xience $(-0.46$ $\pm 1.22 \mathrm{~mm}^{2}$ ), has to be underlined. This difference in behavior is highly significant $(p<0.001)$ and may be explained by the shrinking of the primary and short lasting inflammatory reaction due to the barotrauma in the metallic drug eluting sten t [3], while in BRS the secondary long lasting phase of inflammatory reaction is mainly due to the bioresorption of the polymer and generates an increase in plaque-media area (plaque burden) that contributes certainly to the increase in the vessel area [22].

In contrast, in the DES arm, there was no significant difference in change in the lumen, plaque vessel area and plaque burden amongst the 3 terciles of ESS post-procedure.

In BRS, increase in mean lumen area resulted in lowering of the 
Table 3

Multivariate model predicting vessel area change $\left(\mathrm{mm}^{2}\right)$ over 3 years.

\begin{tabular}{|c|c|c|c|c|c|c|c|c|c|}
\hline & \multicolumn{3}{|l|}{ Overall } & \multicolumn{3}{|l|}{ Absorb } & \multicolumn{3}{|l|}{ Xience } \\
\hline & coefficient & $95 \% \mathrm{CI}$ & $p$ value & coefficient & $95 \% \mathrm{CI}$ & $p$ value & coefficient & $95 \% \mathrm{CI}$ & $p$ value \\
\hline Age (per year) & -0.07 & $(-0.21,0.07)$ & 0.329 & -0.22 & $(-0.39,-0.04)$ & 0.016 & 0.09 & $(-0.10,0.28)$ & 0.330 \\
\hline Female & 0.57 & $(-2.61,3.75)$ & 0.715 & 0.54 & $(-2.10,3.19)$ & 0.676 & 3.11 & $(-6.69,12.92)$ & 0.510 \\
\hline Absorb implantation & 0.04 & $(-2.67,2.75)$ & 0.975 & NA & & & & & \\
\hline \multicolumn{10}{|l|}{ IVUS post-procedure } \\
\hline Vessel area (per $\mathrm{mm}^{2}$ ) & -0.74 & $(-0.92,-0.56)$ & $<0.001$ & -0.70 & $(-0.92,-0.48)$ & $<0.001$ & -0.92 & $(-1.27,-0.56)$ & $<0.001$ \\
\hline Lumen area (per $\mathrm{mm}^{2}$ ) & 0.78 & $(0.43,1.13)$ & $<0.001$ & 0.66 & $(0.19,1.12)$ & 0.006 & 1.16 & $(0.59,1.73)$ & $<0.001$ \\
\hline Plaque area $\left(\right.$ per $\left.\mathrm{mm}^{2}\right)$ & $\mathrm{NA}^{\mathrm{a}}$ & & & & & & & & \\
\hline Plaque burden (per \%) & 0.10 & $(0.06,0.15)$ & $<0.001$ & 0.10 & $(0.05,0.15)$ & $<0.001$ & 0.14 & $(0.05,0.24)$ & 0.002 \\
\hline Median ESS post-procedure (per Pa) & 0.45 & $(0.01,0.89)$ & 0.046 & 0.59 & $(0.16,1.01)$ & 0.009 & 0.21 & $(-1.12,1.54)$ & 0.740 \\
\hline
\end{tabular}

$\mathrm{CI}=$ confidence interval, ESS = endothelial shear stress, IVUS = intravascular ultrasound, NA = not available.

a Not shown because it is redundant.

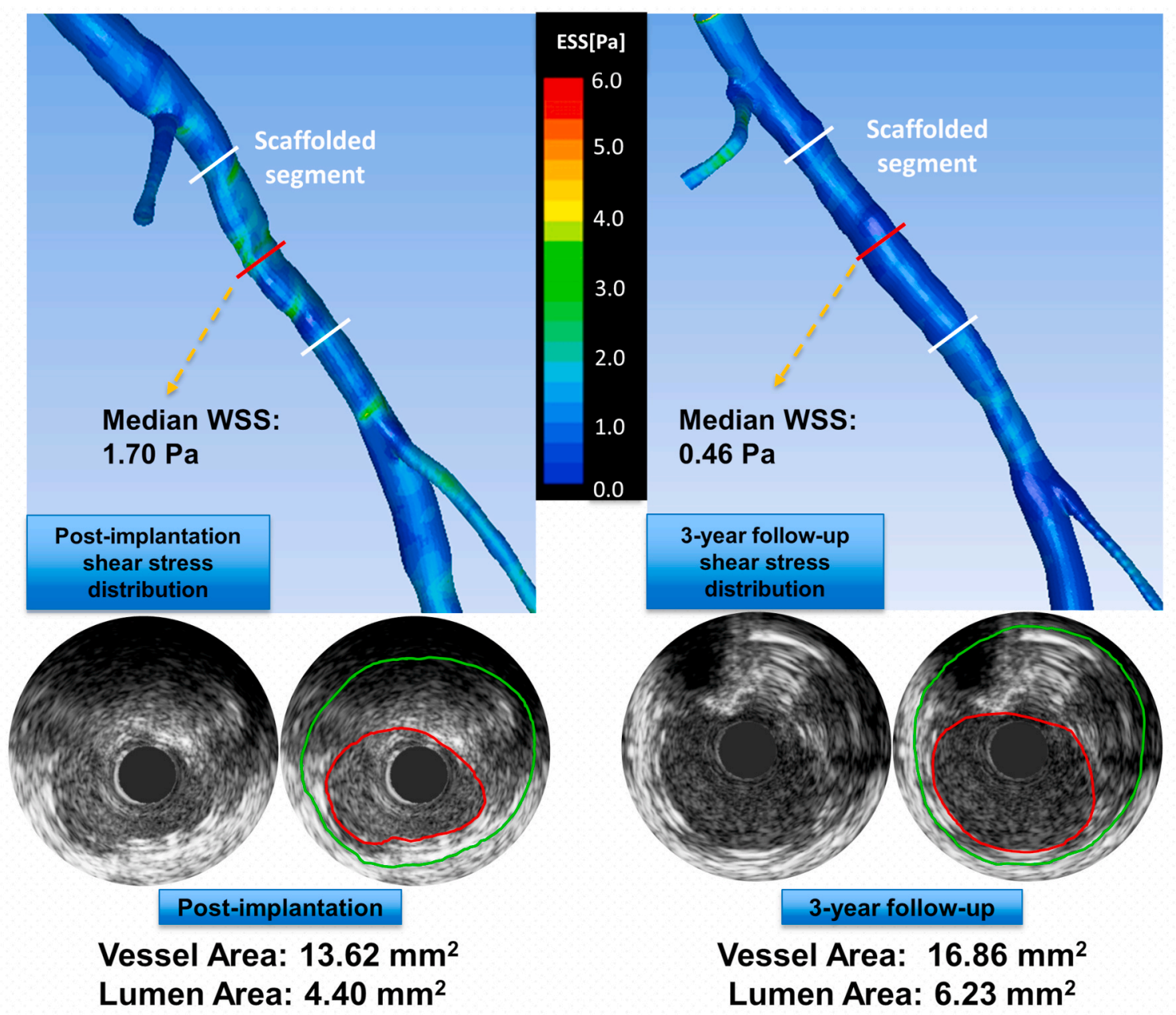

Fig. 5. Post-procedural endothelial shear stress and changes in IVUS parameters during 3 years in a case of expansive remodeling in BRS.

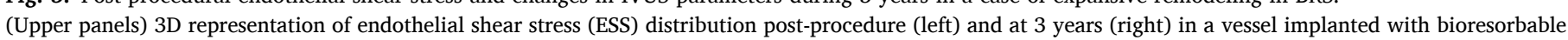

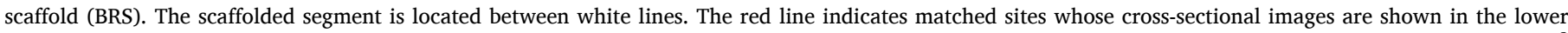

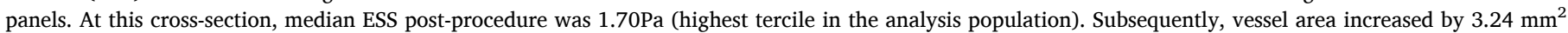

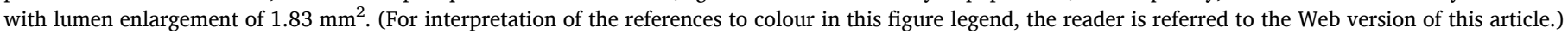

median ESS over 3 years, which is expected from the standard fluid dynamic laws, and illustrated in Fig. 5 [23].

\subsection{Predictors of vessel remodeling}

\subsubsection{Endothelial shear stress post-procedure}

Higher ESS was one of the independent predictors of expansive remodeling. This is in line with other previous studies in native vessels [24-26]. High ESS can stimulate the production of metalloproteinases by macrophages, which could contribute to expansive remodeling [27, 28]. On the contrary, in lesions implanted with bare metal stent or DES, ESS did not impact on vessel remodeling in IBIS-4 [29]. It is of note that BRS had $p$-value $<0.10$ in univariate analysis; however, in the multivariate model, it was not retained while ESS was with a significant 
$p$-value. This fact indicates that the device type would impose restriction on remodeling (i.e. metallic DES would restrict remodeling whereas BRS would not). The dismantling of the polymeric structure and the inflammatory reaction around the polymeric struts permit the shear stress to act on the vessel wall in BRS. The durable skeleton of the metallic stent could not provide such a flexible "environment" for shear stress, precluding its influence on the vessel wall. Instead of outward expansive remodeling with potentially late lumen enlargement, seen with the polymeric scaffold, in metallic stents relatively high ESS could only prevent an exuberant intrastent neointimal hyperplasia. Lower ESS had raising effect for vessel area however compared to the higher ESS it was significantly less. Nevertheless, lower ESS had decremental effect on the lumen area contrary to higher ESS.

On the other hand, to explain the vessel long-term behaviors only with ESS value measured at a one-time point -post-implantation ESS or ESS at 3 years-may be problematic. Due to its nature, shear stress is not a static entity. It has a dynamic behavior which closely depends on the temporal and spatial changes within the flow area [30]; teleologically, the response to a decreased shear stress post-implantation of the scaffold will be a narrowing of the vessel lumen in order to restore the shear stress in its physiological range. Conversely, high post-implantation shear stress will regulate mechanotransduction processes that will result in an enlargement of lumen and vessel area of the scaffold,-as soon as its mechanical integrity has subsided-to eventually decrease the shear stress level back to physiological range (1-7Pa) [31].

\subsubsection{Post-procedural vessel, lumen area and plaque burden}

Smaller post-procedural vessel area was independently associated with expansive remodeling. A similar relationship was already observed by Zarins et al. in pressure-perfusion-fixed postmortem adult human coronary arteries [32]. In other words, the smaller the vessel is, the more capable it is of expansive remodeling. In the Absorb group there is some relationship between change in vessel area and lumen area, between lumen area and plaque burden and relative change in lumen area and $\mathrm{ESS}\left(\mathrm{R}^{2}=0.310\right)$. In the Xience group, such relationship between lumen area and wall shear stress $\left(\mathrm{R}^{2}=0.005\right)$ does not exist (Fig. 4).

Larger lumen area post-procedure is another independent predictor of expansive remodeling. Larger lumen area could be either due to good scaffold/stent expansion or large vessel size. In our previous study, with a sample size of 501 patient, high balloon-artery ratio was a predictor of expansive remodeling [3], and could have resulted in larger lumen area.

Glagov et al. reported that lumen area is preserved until plaque burden reaches $40-50 \%$ of the vessel area, as a result of a compensatory expansive remodeling [5]. However, beyond the value of $40-50 \%$, the compensatory expansive remodeling gets exhausted with subsequent reduction in lumen area, at the pro rata of the increase in plaque burden. Post-procedural plaque burden in the present study population was on average $54.6 \pm 6.0 \%$ (BRS) and $54.3 \pm 5.5 \%$ (DES) in both arms.

\subsubsection{Age and capability of remodeling}

The coefficient of age (per year) in the multivariate model was negative with significant $p$-value only in the stratified analysis in BRS. In other words, younger patients are more prone to show expansive remodeling only in BRS. This could be explained by the fact that matrix metalloproteinase-9, an enzyme which enhances expansive remodeling, decreases as a function of age [33]. Apparently, the relationship of age and remodeling is weaker in the vessel segments caged by metallic DES.

\subsubsection{Tissue component}

In our previous report analyzing vessel remodeling at the device level, pre-procedural necrotic core was significantly associated with expansive remodeling [3]. However, in the present study, none of the tissue components documented by IVUS-VH was retained as a significant predictor of expansive vessel remodeling. A study with larger sample size may unravel interactions between tissue composition, vessel remodeling and ESS.

\subsection{Limitations}

The retrospective nature of this post-hoc study may be subject to a potential selection bias, and thus, the reported results should be regarded as hypothesis-generating. There were also too few events to allow construction of a comprehensive multivariable model that would have explored the value of ESS in predicting clinical outcomes. Although ESS analyses were attempted on the entire randomized population of ABSORB II ( $n=501$ patients), due to eligibility criteria for each step in the study and technical difficulties, a large number of patients had to be excluded. Similarly, in the PROSPECT study, researchers could only include $14 \%$ of the original cohort in the ESS sub-study for comparable reasons [34].

During the matching of the IVUS frames pre-procedural, post-procedural and 3 years at follow up, the researchers used identical landmarks such as scaffold/stent edges, side-branches and calcium locations so that serial changes of the lumen plaque, vessel area and ESS from post-procedure to 3 years could be analyzed at a cross-sectional level. Inter-observer variability was not assessed during the matching process and might potentially have inevitable impact on the results.

Assumptions are inevitable in computational flow modeling. Our models include side branches and non-Newtonian blood behavior - both of which are often simplified more - and the only major assumption was the steady state flow condition. It has been shown that steady flow condition captures well the time-averaged shear stress [35] and is used as an effective predictor of disease progression [18]. Pulsatile flow condition would be required in case the oscillatory nature of flow and shear stress is of interest [36], which is warranted as our future study.

CFD was applied to compute ESS in the stented segments, and several assumptions were made, potentially effecting the accuracy of the computations. The most prominent assumption deals with applying scaling laws to estimate the flow rates in the main branch and the side branches. This assumption can influence average ESS values up to 8\% [15]. It has to be noted though that the largest impact was seen near side branches, so we expect a smaller effect in the stented segments.

In future studies investigating the effect of ESS and vessel remodeling, a hybrid IVUS-OCT catheter may be preferred, as it could measure concomitantly lumen area, vessel area, plaque-media area and micro flow disturbance with precise co-registration, as recommended in the expert consensus on ESS [31].

\subsection{What is already known?}

In bioresorbable scaffold (BRS) due to lower radial force, the lumen area post-implantation is smaller than the metallic stent. Due to smaller lumen area in BRS, endothelial shear stress (ESS) is relatively higher in BRS than in metallic stent. At follow up, with higher shear stress and the degradation of the polymeric scaffold, the vessel remodels and the vessel area start to expand. On the other hand, in metallic stents, there is no such opportunity of structural modification in the vessel wall due to the fixed metallic cage. Instead, the neointimal hyperplasia increases inside the metallic cage with a reduction in lumen area. Shear stress has impact on neointimal hyperplasia in the metallic caged vessel segments.

\subsection{What does this study add?}

Shear stress had significant influence on the expansive behavior of the BRS implanted vessels whereas no such effect was noted in metallic caged vessel segments. The present study is the first to reveal that high shear stress may have impact on expansion of the vessels instrumented with polymeric scaffolds.

\subsection{How might this impact on clinical practice?}

The development in the 3D vessel reconstruction and 3D CFD modeling may facilitate virtually the planning of stent/scaffold 
implantation prior to PCI in the cath-lab. In the future, with ultra-highspeed computers, "online CFD simulation" may provide assessment of the optimized implantation of the polymeric scaffold. Virtual stenting enables planning and selection of an optimal treatment strategy. Postimplantation shear stress assessment may provide insights into the hemodynamic micro-environment and this may shed light on the potential vascular behaviors at long-term follow up that can alert the clinicians for any potential adverse events.

\subsection{Conclusions}

Coronary segments implanted with BRS were exposed to higher ESS post-procedure as compared to DES. Post-procedural higher median ESS, smaller vessel area, and higher plaque burden were independent predictors of expansive remodeling and late lumen enlargement at 3 years. Only in the BRS, younger age was an additional significant predictor of expansive remodeling.

\section{Clinical trial registration}

Https://clinicaltrials.gov/ct2/show/NCT01425281 (Unique Identifier: NCT01425281).

\section{Financial support}

Dr. Tenekecioglu has a research grant from TUBITAK (The Research and Scientific Council of Turkey). Dr. Sabaté reports grants and personal fees from Abbott Vascular. Dr. Piek reports non-financial support from Member medical advisory board Abbott Vascular, personal fees and nonfinancial support from Consultant Philips/Volcano. Dr. Wykrzykowska reports grants and personal fees from Abbott. Johan H.C. Reiber is CEO, and Pieter Kitslaar is an employee of Medis medical imaging systems bv, Leiden. Dr. Chevalier reports personal fees from Abbott Vascular; personal fees from Cordis, personal fees from Biotronik, from Medtronic, personal fees from Terumo, other from CERC. Y. Onuma is a member of the advisory board of Abbott Vascular. P.W. Serruys is a member of the advisory board of Abbott Vascular. All the other authors have nothing to declare.

\section{CRediT authorship contribution statement}

Erhan Tenekecioglu: Design of the study, Writing - original draft, Critical revision of the manuscript, Formal analysis, Writing - review \& editing. Yuki Katagiri: Design of the study, Writing - original draft, Critical revision of the manuscript, Writing - review \& editing, Formal analysis. Kuniaki Takahashi: Design of the study. Mariusz Tomaniak: Critical revision of the manuscript. Dariusz Dudek: Data curation, Critical revision of the manuscript. Angel Cequier: Data curation. Didier Carrié: Data curation. Andrés Iñiguez: Data curation. Rinse Johannes van der Schaaf: Data curation. Marcello Dominici: Data curation. Ad J.van Boven: Data curation. Steffen Helqvist: Data curation. Manel Sabaté: Data curation. Andreas Baumbach: Data curation. Jan J. Piek: Data curation. Joanna J. Wykrzykowska: Data curation. Pieter Kitslaar: Data curation. Jouke Dijkstra: Design of the study. Johan H.C. Reiber: Design of the study. Bernard Chevalier: Data curation. Dilek Ural: Writing - review \& editing. Kerem Pekkan: Design of the study, Design of the study, Critical revision of the manuscript, Writing - review \& editing. Christos V. Bourantas: Critical revision of the manuscript. Frank Gijsen: Design of the study, Data curation, Writing - original draft, Critical revision of the manuscript, Writing - review \& editing. Yoshinobu Onuma: Design of the study, Writing - original draft, Critical revision of the manuscript, Formal analysis, Writing - review \& editing. Ryo Torii: Design of the study, Writing - original draft, Critical revision of the manuscript, Writing review \& editing. Patrick W. Serruys: Design of the study, Writing review \& editing, Critical revision of the manuscript, Writing - original draft, Data curation.

\section{Declaration of competing interest}

The authors declared they do not have anything to disclose regarding conflict of interest with respect to this manuscript.

\section{Appendix A. Supplementary data}

Supplementary data to this article can be found online at https://doi. org/10.1016/j.atherosclerosis.2020.08.031.

\section{References}

[1] P.W. Serruys, H.M. Garcia-Garcia, Y. Onuma, From metallic cages to transient bioresorbable scaffolds: change in paradigm of coronary revascularization in the upcoming decade? Eur. Heart J. 33 (1) (2012) 16-25b.

[2] G. Masiero, M. Mojoli, D. Ueshima, G. Tarantini, Current concepts on coronary revascularization using BRS in patients with diabetes and small vessels disease, J. Thorac. Dis. 9 (Suppl 9) (2017) S940-S949.

[3] P.W. Serruys, Y. Katagiri, Y. Sotomi, Y. Zeng, B. Chevalier, R.J. van der Schaaf, A. Baumbach, P. Smits, N.M. van Mieghem, A. Bartorelli, et al., Arterial remodeling after bioresorbable scaffolds and metallic stents, J. Am. Coll. Cardiol. 70 (1) (2017) after bi 74 .

[4] Z.S. Galis, J.J. Khatri, Matrix metalloproteinases in vascular remodeling and atherogenesis: the good, the bad, and the ugly, Circ. Res. 90 (3) (2002) 251-262.

[5] S. Glagov, E. Weisenberg, C.K. Zarins, R. Stankunavicius, G.J. Kolettis, Compensatory enlargement of human atherosclerotic coronary arteries, N. Engl. J. Med. 316 (22) (1987) 1371-1375.

[6] C.A. Van Mieghem, N. Bruining, J.A. Schaar, E. McFadden, N. Mollet, F. Cademartiri, F. Mastik, J.M. Ligthart, G.A. Granillo, M. Valgimigli, et al., Rationale and methods of the integrated biomarker and imaging study (IBIS): combining invasive and non-invasive imaging with biomarkers to detect subclinical atherosclerosis and assess coronary lesion biology, Int. J. Cardiovasc. Imag. 21 (4) (2005) 425-441.

[7] N. Resnick, H. Yahav, A. Shay-Salit, M. Shushy, S. Schubert, L.C. Zilberman, E. Wofovitz, Fluid shear stress and the vascular endothelium: for better and for worse, Prog. Biophys. Mol. Biol. 81 (3) (2003) 177-199.

[8] M. Heil, W. Schaper, Influence of mechanical, cellular, and molecular factors on collateral artery growth (arteriogenesis), Circ. Res. 95 (5) (2004) 449-458.

[9] Serruys PW, Chevalier B, Sotomi Y, Cequier A, Carrié D, Piek JJ, Van Boven AJ, Dominici M, Dudek D, McClean D et al: Comparison of an everolimus-eluting bioresorbable scaffold with an everolimus-eluting metallic stent for the treatment of coronary artery stenosis (ABSORB II): a 3 year, randomised, controlled, singleblind, multicentre clinical trial. Lancet, 388(10059):2479-2491.

[10] G.S. Mintz, S.E. Nissen, W.D. Anderson, S.R. Bailey, R. Erbel, P.J. Fitzgerald, F. J. Pinto, K. Rosenfield, R.J. Siegel, E.M. Tuzcu, et al., American college of cardiology clinical expert consensus document on standards for acquisition, measurement and reporting of intravascular ultrasound studies (IVUS). A report of the American college of cardiology task force on clinical expert consensus documents, J. Am. Coll. Cardiol. 37 (5) (2001) 1478-1492.

[11] P.W. Serruys, M. Degertekin, K. Tanabe, M.E. Russell, G. Guagliumi, J. Webb, J. Hamburger, W. Rutsch, C. Kaiser, R. Whitbourn, et al., Vascular responses at proximal and distal edges of paclitaxel-eluting stents: serial intravascular ultrasound analysis from the TAXUS II trial, Circulation 109 (5) (2004) 627-633.

[12] T. Muramatsu, H.M. Garcia-Garcia, S. Brugaletta, J.H. Heo, Y. Onuma, R. J. Fedewa, A. Nair, Y. Ozaki, P.W. Serruys, Reproducibility of intravascular ultrasound radiofrequency data analysis (virtual histology) with a $45-\mathrm{MHz}$ rotational imaging catheter in ex vivo human coronary arteries, J. Cardiol. 65 (2) (2015) 134-142.

[13] M.I. Papafaklis, C.V. Bourantas, V. Farooq, R. Diletti, T. Muramatsu, Y. Zhang, D. I. Fotiadis, Y. Onuma, H.M. Garcia Garcia, L.K. Michalis, et al., In vivo assessment of the three-dimensional haemodynamic micro-environment following drugeluting bioresorbable vascular scaffold implantation in a human coronary artery: fusion of frequency domain optical coherence tomography and angiography, EuroIntervention : journal of EuroPCR in collaboration with the Working Group on Interventional Cardiology of the European Society of Cardiology 9 (7) (2013) 890.

[14] A. Manbachi, Y. Hoi, B.A. Wasserman, E.G. Lakatta, D.A. Steinman, On the shape of the common carotid artery with implications for blood velocity profiles, Physiol. Meas. 32 (12) (2011) 1885-1897.

[15] A.G. van der Giessen, H.C. Groen, P.A. Doriot, P.J. de Feyter, A.F. van der Steen, F. N. van de Vosse, J.J. Wentzel, F.J. Gijsen, The influence of boundary conditions on wall shear stress distribution in patients specific coronary trees, J. Biomech. 44 (6) (2011) 1089-1095.

[16] T. Seo, L.G. Schachter, A.I. Barakat, Computational study of fluid mechanical disturbance induced by endovascular stents, Ann. Biomed. Eng. 33 (4) (2005) 444-456.

[17] J.T. Schrauwen, J.C. Schwarz, J.J. Wentzel, A.F. van der Steen, M. Siebes, F. J. Gijsen, The impact of scaled boundary conditions on wall shear stress computations in atherosclerotic human coronary bifurcations, Am. J. Physiol. Heart Circ. Physiol. 310 (10) (2016) H1304-H1312. 
[18] P.H. Stone, S. Saito, S. Takahashi, Y. Makita, S. Nakamura, T. Kawasaki, A. Takahashi, T. Katsuki, S. Nakamura, A. Namiki, et al., Prediction of progression of coronary artery disease and clinical outcomes using vascular profiling of endothelial shear stress and arterial plaque characteristics: the PREDICTION Study, Circulation 126 (2) (2012) 172-181.

[19] Y. Sotomi, Y. Ishibashi, P. Suwannasom, S. Nakatani, Y.K. Cho, M.J. Grundeken, Y. Zeng, H. Tateishi, P.C. Smits, P. Barragan, et al., Acute gain in minimal lumen area following implantation of everolimus-eluting ABSORB biodegradable vascular scaffolds or xience metallic stents: intravascular ultrasound assessment from the ABSORB II trial, JACC Cardiovasc. Interv. 9 (12) (2016) 1216-1227.

[20] V. Thondapu, E. Tenekecioglu, E.K.W. Poon, C. Collet, R. Torii, C.V. Bourantas, C. Chin, Y. Sotomi, H. Jonker, J. Dijkstra, et al., Endothelial shear stress 5 years after implantation of a coronary bioresorbable scaffold, Eur. Heart J. 39 (18) (2018) 1602-1609.

[21] E. Tenekecioglu, R. Torii, Y. Katagiri, T. Asano, R. Modolo, Y. Miyazaki, P. Chichareon, E.K.W. Poon, F. Gijsen, V. Thondapu, et al., Early strutprotrusion and late neointima thickness inAbsorb bioresorbable scaffold: a serial wallshear stress analysis up to five years, EuroIntervention 15 (4) (2019) e370-e379.

[22] F. Otsuka, E. Pacheco, L.E. Perkins, J.P. Lane, Q. Wang, M. Kamberi, M. Frie, J. Wang, K. Sakakura, K. Yahagi, et al., Long-term safety of an everolimus-eluting bioresorbable vascular scaffold and the cobalt-chromium XIENCE V stent in a porcine coronary artery model, Circulation Cardiovascular interventions 7 (3) (2014) 330-342.

[23] R.E. Klabunde, Cardiovascular Physiology Concepts, second ed., Lippincott Williams \& Wilkins/Wolters Kluwer, Philadelphia, PA, 2012.

[24] P.H. Stone, A.U. Coskun, S. Kinlay, J.J. Popma, M. Sonka, A. Wahle, Y. Yeghiazarians, C. Maynard, R.E. Kuntz, C.L. Feldman, Regions of low endothelial shear stress are the sites where coronary plaque progresses and vascular remodelling occurs in humans: an in vivo serial study, Eur. Heart J. 28 (6) (2007) 705-710.

[25] H. Samady, P. Eshtehardi, M.C. McDaniel, J. Suo, S.S. Dhawan, C. Maynard, L. H. Timmins, A.A. Quyyumi, D.P. Giddens, Coronary artery wall shear stress is associated with progression and transformation of atherosclerotic plaque and arterial remodeling in patients with coronary artery disease, Circulation 124 (7) (2011) 779-788.

[26] M.T. Corban, P. Eshtehardi, J. Suo, M.C. McDaniel, L.H. Timmins, E. RassoulArzrumly, C. Maynard, G. Mekonnen, S. King 3rd, A.A. Quyyumi, et al., Combination of plaque burden, wall shear stress, and plaque phenotype has incremental value for prediction of coronary atherosclerotic plaque progression and vulnerability, Atherosclerosis 232 (2) (2014) 271-276.

[27] A.K. Death, S. Nakhla, K.C. McGrath, S. Martell, D.K. Yue, W. Jessup, D, S. Celermajer, Nitroglycerin upregulates matrix metalloproteinase expression by human macrophages, J. Am. Coll. Cardiol. 39 (12) (2002) 1943-1950.
[28] C.J. Slager, J.J. Wentzel, F.J. Gijsen, J.C. Schuurbiers, A.C. van der Wal, A.F. van der Steen, P.W. Serruys, The role of shear stress in the generation of rupture-prone vulnerable plaques, Nat. Clin. Pract. Cardiovasc. Med. 2 (8) (2005) 401-407.

[29] C.V. Bourantas, L. Raber, S. Zaugg, A. Sakellarios, M. Taniwaki, D. Heg, A. Moschovitis, M. Radu, M.I. Papafaklis, F. Kalatzis, et al., Impact of local endothelial shear stress on neointima and plaque following stent implantation in patients with ST-elevation myocardial infarction: a subgroup-analysis of the COMFORTABLE AMI-IBIS 4 trial, Int. J. Cardiol. 186 (2015) 178-185.

[30] K.C. Koskinas, C.L. Feldman, Y.S. Chatzizisis, A.U. Coskun, M. Jonas, C. Maynard, A.B. Baker, M.I. Papafaklis, E.R. Edelman, P.H. Stone, Natural history of experimental coronary atherosclerosis and vascular remodeling in relation to endothelial shear stress: a serial, in vivo intravascular ultrasound study, Circulation 121 (19) (2010) 2092-2101.

[31] F. Gijsen, Y. Katagiri, P. Barlis, C. Bourantas, C. Collet, U. Coskun, J. Daemen, J. Dijkstra, E. Edelman, P. Evans, K. van der Heiden, R. Hose, B.K. Koo, R. Krams, A. Marsden, F. Migliavacca, Y. Onuma, A. Ooi, E. Poon, H. Samady, P. Stone, K. Takahashi, D. Tang, V. Thondapu, E. Tenekecioglu, L. Timmins, R. Torii, J. Wentzel, P. Serruys, Eur Heart J 40 (41) (2019) 3421-3433.

[32] C.K. Zarins, E. Weisenberg, G. Kolettis, R. Stankunavicius, S. Glagov, Differentia enlargement of artery segments in response to enlarging atherosclerotic plaques, J. Vasc. Surg. 7 (3) (1988) 386-394.

[33] D.D. Bonnema, C.S. Webb, W.R. Pennington, R.E. Stroud, A.E. Leonardi, L.L. Clark, C.D. McClure, L. Finklea, F.G. Spinale, M.R. Zile, Effects of age on plasma matrix metalloproteinases (MMPs) and tissue inhibitor of metalloproteinases (TIMPs), J. Card. Fail. 13 (7) (2007) 530-540.

[34] P.H. Stone, A. Maehara, A.U. Coskun, C.C. Maynard, M. Zaromytidou, G. Siasos, I. Andreou, D. Fotiadis, K. Stefanou, M. Papafaklis, et al., Role of low endothelial shear stress and plaque characteristics in the prediction of nonculprit major adverse cardiac events: the PROSPECT study, JACC Cardiovascular imaging 11 (3) (2018) 462-471.

[35] E. Tenekecioglu, R. Torii, C. Bourantas, T. Crake, Y. Zeng, Y. Sotomi, Y. Onuma, M. Yilmaz, T. Santoso, P.W. Serruys, Preclinical assessment of the endothelial shear stress in porcine-based models following implantation of two different bioresorbable scaffolds: effect of scaffold design on the local haemodynamic microenvironment, EuroIntervention : journal of EuroPCR in collaboration with the Working Group on Interventional Cardiology of the European Society of Cardiology 12 (10) (2016) 1296.

[36] A.M. Kok, D.S. Molony, L.H. Timmins, Y.A. Ko, E. Boersma, P. Eshtehardi, J. J. Wentzel, H. Samady, The influence of multidirectional shear stress on plaque progression and composition changes in human coronary arteries, in: EuroIntervention : Journal of EuroPCR in Collaboration with the Working Group on Interventional Cardiology of the European Society of Cardiology, 2019. 